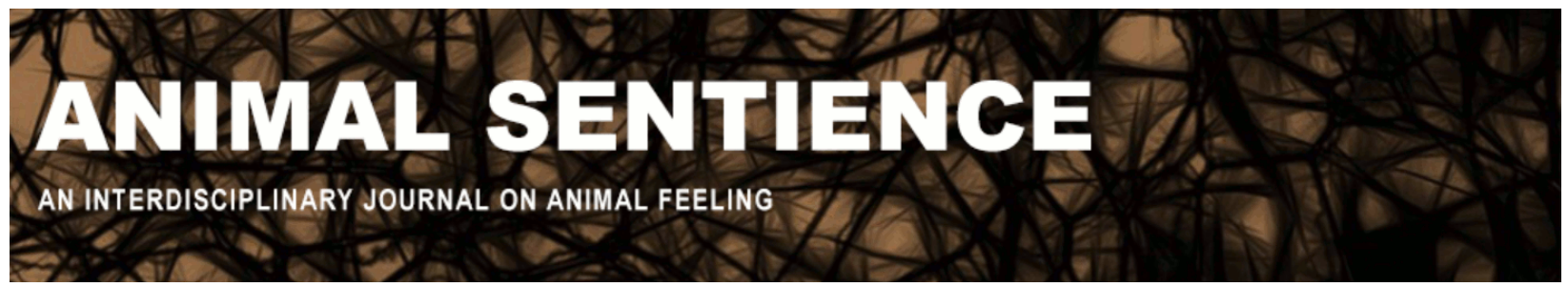

Harmon-Jones, Cindy; Haslam, Nick; and Bastian, Brock (2017) Dissonance reduction in nonhuman animals: Implications for cognitive dissonance theory. Animal Sentience 12(4) DOI: $10.51291 / 2377-7478.1191$

Date of submission: 2017-01-31 Date of acceptance: 2017-02-13

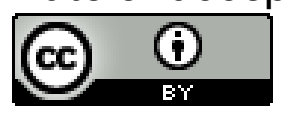




\title{
Dissonance reduction in nonhuman animals: Implications for cognitive dissonance theory
}

Commentary on Zentall on Cognitive Dissonance

\author{
Cindy Harmon-Jones \\ University of New South Wales \\ Nick Haslam \\ University of Melbourne \\ Brock Bastian \\ University of Melbourne
}

\begin{abstract}
We review the evidence for dissonance reduction in nonhuman animals and examine the alternative explanations for these effects. If nonhuman animals engage in dissonance reduction, this supports the original theory as proposed by Festinger (1957) over the revisions to the theory that focused on the self-concept. Evidence of animal sentience, including dissonance reduction, may be a source of cognitive dissonance.
\end{abstract}

\footnotetext{
Cindy Harmon-Jones, postdoctoral fellow, University of New South Wales, does research on motivation, approach-motivated and negative emotions such as anger, cognitive dissonance affect, positive emotions

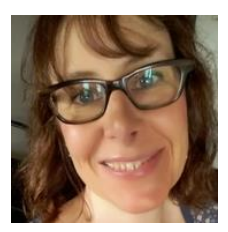
such as determination, and positive effects of pain. She developed the action-based model of dissonance with Eddie Harmon-Jones.

https://www.researchgate.net/profile/Cindy_Harmon-Jones
}

Nick Haslam, Professor and Head of the School of Psychological Sciences at the University of Melbourne, does research on personality, social perception and psychiatric classification.

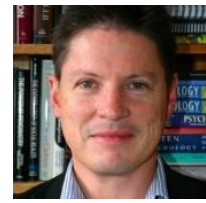

http://findanexpert.unimelb.edu.au/display/person6837

Brock Bastian, ARC Research Fellow, University of New South Wales, does research on pain, happiness, and morality.

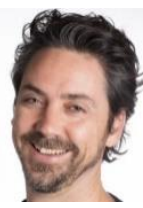

http://findanexpert.unimelb.edu.au/display/person11111

In the target article, Zentall (2016) argues that the behaviors that appear to indicate effort justification in nonhuman animals are more parsimoniously explained by contrast effects. However, explaining similar behaviors in humans and other animals by different mechanisms lacks parsimony. A more elegant explanation would provide a common mechanism for similar responses across species. 
This commentary comes from the perspective of the original theory of dissonance, rather than the human-centric views of the dissonance revisionists, which rely on the concept of "self" and are discussed later in this commentary. We assume that evoking and reducing dissonance is motivated by discrepancies between important cognitions, not necessarily by complex constructs such as self-image or hypocrisy. Before addressing the specifics of the target article, it will be important to review the controversies around dissonance theory and its revisions. Then we will explain the importance of evidence of dissonance processes in nonhuman animals in support of the original theory of cognitive dissonance over the revisions. We will also address the motivation to deny animal sentience according to cognitive dissonance theory.

\section{The original theory of cognitive dissonance and its human-centric revisions}

When Festinger (1957) proposed the theory of cognitive dissonance, he presented it as a broad theory that could apply to any organism with rudimentary cognitive functions. The theory stated that when individuals hold cognitions that are inconsistent with one another, they experience negative affect which motivates mental work to bring the cognitions closer to consistency. He further proposed that the magnitude of this negative affect depends on the number of cognitions consonant and dissonant with the cognition in question, as well as their importance. The cognitions are evaluated in terms of their relationship to the cognition that is most resistant to change, which is known as the generative cognition (Beauvois \& Joule, 1996), and attitude change will move in the direction of this cognition.

The original theory was broad and general enough to apply to myriad situations. Although Festinger (1957) originally proposed the theory in the context of human cognition and behavior, it is simple enough to operate in any organism sufficiently complex to hold two cognitions, or elements of knowledge, that conflict with one another. However, it was not long before dissonance theorists proposed changes to the theory that narrowed its scope. The revisions tended to be more human-centric, focusing on complex and abstract cognitions about the self-concept, constructs which are presumably absent or weak in most nonhuman animals.

According to the first revision of dissonance theory, self-consistency theory, proposed by Aronson (1968), dissonance reduction is motivated by threats to the self-concept, rather than by simple inconsistencies between important cognitions. Since most individuals have positive self-concepts, dissonance is most often evoked by engaging in behavior that appears irrational, incompetent, or immoral. Cooper and Fazio (1984) proposed a second revision, the "New Look," which further narrowed the scope of dissonance theory, holding that dissonance will only be evoked when one believes that one's actions have harmed another person. Finally, according to Steele's (1988) self-affirmation theory, the motivation for attitude change is to maintain an overall self-image of moral and adaptive adequacy. Steele conducted experiments to show that engaging in behavior that violates one's beliefs threatens the self-image, but that a positive self-image can be restored by affirming any important value, not necessarily one related to the specific inconsistency.

All of these self-focused versions of dissonance theory would seem to be inapplicable to nonhuman animals, who presumably lack complex evaluations and motivations around their self-concepts. However, in the 1990s, several researchers began to challenge the complex, restricted versions of dissonance, presenting evidence in support of the original theory (Harmon-Jones, Brehm, Greenberg, Simon, \& Nelson, 1996; Simon, Greenberg, \& Brehm, 
1995). Their experiments suggested that dissonance can be evoked by simple inconsistencies between cognitions, and that these are sufficient to motivate attitude change. Evidence that nonhuman animals demonstrate effort justification (Zentall \& Singer, 2007) and spreading of alternatives (Egan, Santos, \& Bloom, 2007; Egan, Bloom, \& Santos, 2010) also provides important support for the original theory over the revisions that emphasize cognitions about the self-concept.

\section{Comment on Zentall's target article}

Zentall questions the proposition that nonhuman animals have "beliefs" that can be in conflict with one other. In our view, however, beliefs need not be complex or consciously held. A belief (or cognition) may simply be an awareness or expectation. In the case of unpleasant effort, the conflicting cognitions are, "I am engaging in unpleasant effort," and "I would prefer not to." Even cognitively simple organisms could be aware of undergoing an unpleasant experience that is not desired. According to dissonance theory, receiving a reward for the unpleasant effort serves as a consonant cognition for engaging in the effort, and thus elevating the attractiveness of the reward reduces the negative affect due to dissonance. These cognitions need not be highly developed or self-focused, and the cognitive changes do not require conscious awareness.

The target article reports the results of a number of studies showing that pigeons prefer conditioned stimuli that they have exerted more effort to obtain over those they exerted less effort to obtain. These results are consistent with the predictions of dissonance theory. However, Zentall argues that these effects could be due simply to contrast effects. According to this account, the pigeons preferred the rewards following unpleasant effort because the rewards felt more desirable in contrast to the unpleasant event that preceded them.

Contrast effects were proposed as an alternative explanation for effort justification effects in human participants in the early years of dissonance theory. In an ingenious experimental test of this idea, Gerard and Mathewson (1966) compared the evaluation of a target stimulus as a result of undergoing an unpleasant experience that was either in pursuit of a goal or was not associated with achieving a goal. They assigned female participants to receive either painful or very mild shocks, and informed them that the shocks were either a test to see whether they could join a group (initiate condition) or were unrelated to the group (non-initiate condition). After receiving the shocks, participants listened to and evaluated a recording of a very boring group discussion after either being told they had passed the initiation and would now be part of the group (initiate condition) or simply as another unrelated task (non-initiate condition). As predicted by dissonance theory, participants in the initiate condition rated the group more positively, and significantly moreso in the painful shock condition. Contrary to the hypothesis of a contrast effect, participants in the non-initiate condition rated the group more negatively if they had received painful shocks than if they had received non-painful shocks.

These results are consistent with other human research on the effects of unpleasant experiences. For example, in the field of behavioral economics, unpleasant effort has been shown to cause individuals to de-value a goal, a process known as "effort discounting." In studies on effort discounting, unlike research on effort justification, participants are explicitly informed that their reward does not depend on their performance on the task and will be the same whether the task is hard or easy (Botvinick, Huffstetler, \& McGuire, 2009). Similarly, research on "affect infusion" shows that individuals who are in a negative mood after 
undergoing an unpleasant experience often evaluate subsequent experiences more negatively, rather than more positively as would be predicted by a contrast effect (Forgas, 1995). According to dissonance theory, this is because effort justification is predicated on an expectation that one's unpleasant effort was necessary to obtain the goal. If the subsequent event is unrelated to the effort, then elevating its attractiveness will not reduce dissonance affect.

In the target article, Zentall notes that in research on both human children and adults rewarded with shapes following few or many mouse-clicks, participants preferred the shapes that followed many clicks (Alessandri, Darcheville, \& Zentall, 2008; Klein, Bhatt, \& Zentall, 2005). Importantly, the majority of participants were unaware that the shapes were associated with greater effort. Like the evidence of dissonance processes in nonhuman animals, this research supports the original theory of dissonance rather than the revisions, as it suggests that dissonance may be evoked implicitly and need not be a high-level, consciously held belief about the self.

The target article also notes the recent controversy regarding spreading of alternatives, another form of dissonance reduction. In a typical experiment, an individual makes a choice between two highly valued alternatives. The dissonance is caused by positive aspects of the unchosen alternative and negative aspects of the chosen alternative, both of which are discrepant with the choice. Typically, individuals reduce this dissonance by elevating the value of the chosen alternative and/or decreasing the value of the rejected.

As mentioned in the target article, Chen and Risen (2009) proposed an alternative explanation for the spreading-of-alternatives effect, motivated partly by new evidence of this phenomenon in capuchin monkeys and preschool children, both presumably lacking a highly developed self-construct. They argued that simply rating and then re-rating the two alternatives, without choosing between them, would also produce spreading, because the procedure merely revealed existing preferences. They conducted two studies testing this hypothesis with adult humans. Participants viewed and rated posters, then made several choices between posters that they had and had not rated in either the order typical for dissonance studies (rate-choose-rate), or an order that should not evoke dissonance (raterate-choose). In both conditions, there was increased spreading between the chosen and unchosen posters on the second rating. Although mean spreading was greater in the ratechoose-rate condition, as predicted by dissonance theory, this difference was not statistically significant. However, in a second experiment, spreading of alternatives was marginally greater in the rate-choose-rate condition. Thus, the results were consistent with both dissonance theory and revealed preferences theory.

Why was the spreading of alternatives only weakly supportive of dissonance theory in the studies by Chen and Risen (2009)? The particular choices in these experiments may not have been important enough to evoke much dissonance or much dissonance reduction. Participants made 6 choices between posters, and were told only that they would receive one of the posters they chose. They did not expect to receive the critical choice, between two similarly and highly rated alternatives. Typically, in dissonance experiments, participants only make a single choice; this allows them to remember more easily which item they chose and increases the importance of the choice.

Zentall notes that he is unaware of any published research that has addressed this alternative explanation for spreading of alternatives in nonhuman animals. However, Egan, Bloom, and Santos (2010) undertook this using a blind choice paradigm. They showed preschool children two toys and then placed the toys in socks before allowing them to choose 
one toy, so that the children did not know which toy they had chosen until after making the decision. Children subsequently preferred the chosen toy to an alternative toy, as dissonance theory would predict. In a second study, the authors replicated this result using a blind choice paradigm with capuchin monkeys. These results clearly support dissonance reduction, not merely revealed preferences, in nonhuman animals and children.

Zentall states that contrast or effort justification effects, “... need not depend on the social construct of need for consistency between one's beliefs or on the implied social mechanism, the avoidance of hypocrisy" (p. 10). With this we fully concur. This is one reason we have been particularly excited about evidence of dissonance reduction in nonhuman animals: It is consistent with the original theory of dissonance and inconsistent with the revisions which focus on the self-concept. However, the evidence suggests that effort justification and spreading of alternatives are motivated processes, not simply perceptual ones.

\section{Evidence of animal sentience causes cognitive dissonance}

Evidence that animals engage in dissonance-reduction may itself cause dissonance and motivate a search for alternative explanations for these effects. According to Terror Management Theory (TMT), awareness of our "creatureliness" - that is, of our existence as transient bodily organisms similar to other animals - is threatening to humans. It may serve remind us of our own mortality, something humans find deeply threatening to contemplate (Goldenberg, Pyszczynski, Greenberg, Solomon, Kluck, \& Cornwell, 2001). According to dissonance theory, awareness of our own eventual mortality is a highly important cognition that is dissonant with the cognition that we would prefer not to die. The anthropocentric revisions of dissonance theory may help humans avoid death awareness by downplaying the similarities in cognitive processes that we share with nonhuman animals and keeping the focus on higher-level, complex concerns such as the self-concept.

Another reason humans may seek alternative explanations for evidence that animals engage in dissonance reduction is that acknowledging that animals have emotions, motivations and cognitions similar to those of humans produces dissonance related to the human propensity for cruelty toward animals. In support of this idea, Bastian, Loughnan, Haslam, and Radke (2012) showed that reminders of meat-eating caused participants to deny that animals have minds. In the first of three studies, participants were asked to rate the mental capacities and edibility of 32 animals, and the results showed that perceived sentience was negatively related to edibility $(r=-0.42)$, and positively related to how bad that participant would feel about eating the animal $(r=0.77)$. In a second study, participants were shown a photograph of a cow or a sheep, with a statement that this animal either would be killed, butchered and eaten, or that it would be moved to another paddock to graze. Participants then rated the animal's mental capacities, and results showed that when the animal was to be eaten, meat-eating participants denied it mental capacities.

The final study provided the clearest evidence that individuals are motivated to reduce dissonance related to meat-eating by denying that animals are sentient. Participants were informed that they would be participating in a study of consumer preferences and would be sampling foods. They were assigned to sample either meat or fruit, and the food items were placed in front of them. Participants were then asked to write an essay about the processes involved in bringing meat from the farm to the supermarket shelves, including slaughtering the animal. They then rated the mental capacities of the animal they had written about and, 
in the meat-eating condition, expected to eat, as well as an affect measure. Those participants who expected to eat meat showed a significant decrease in their ratings of the mental capabilities of the animal. Furthermore, the decrease in ratings of mental capacities was related to affect. That is, those participants who successfully reduced their dissonance regarding meat-eating, by denying that the animal they were about to eat had sentience, also reduced their dissonance-related negative affect (Bastian et al., 2012).

\section{Why do organisms engage in dissonance reduction?}

One answer is offered by the action-based model of dissonance (Harmon-Jones, Amodio, \& Harmon-Jones, 2009). According to this model, cognitions, broadly defined, have associated action-tendencies. That is, cognitions guide action. When important cognitions are in conflict, their action-tendencies are also likely to be in conflict, and this interferes with effective and conflict-free action. The action-based model is a functional theory of dissonance; it proposes that bringing cognitions into consistent relationships allows the organism to act. This need to act in an effective and conflict-free manner would not be unique to humans but shared by all organisms capable of learning and forming expectations.

In support of this model, evidence has suggested that dissonance reduction is positively related to approach motivation at the trait level (Harmon-Jones, Schmeichel, \& Harmon-Jones, 2010). At the state level, spreading of alternatives is associated with left-frontal cortical activity, a marker of approach orientation (Harmon-Jones, Harmon-Jones, Fearn, \& Sigelman,, 2008). Furthermore, (1) inducing participants to be more approach-motivated by manipulating an action-oriented mindset, thereby enhancing dissonance reduction (Harmon-Jones \& Harmon-Jones, 2002), and (2) reducing approach motivation by using a supine body posture, decreases effort justification (Harmon-Jones, Price, \& Harmon-Jones, 2015). All this evidence suggests that dissonance reduction in humans is an approach-motivated process, not merely a contrast effect nor a defensive, avoidance-motivated process as would be predicted by the self-concept models. The action-based model would predict that dissonance reduction in nonhuman animals is likewise an approach-motivated process that facilitates effective behavior.

Why would effort justification be functional? Zentall suggested a plausible reason in the target article, "One possibility is that when food is scarce, if food that is difficult to obtain (a relatively negative condition) has added value, it might encourage the animal to search longer" (Zentall, 2016, p. 5). Similarly, the action-based model proposes that if one has worked hard to obtain a goal, it is generally functional to value that goal and appreciate its benefits.

\section{Conclusion}

Both the motivation to "humanize" humans and the motivation to "dehumanize" nonhuman animals may be involved in interpretations of dissonance theory. The revisions to the theory have tended toward redefining it as a narrow, human-only process driven by needs for selfconsistency or reputational concerns such as the avoidance of perceived hypocrisy. Similarly, evidence that dissonance processes operate in nonhuman animals are commonly met with alternative explanations denying that these effects really reflect dissonance.

Meanwhile, evidence suggests that viewing animals as sentient in itself evokes dissonance, for at least two reasons. One is that humans are motivated to view themselves as special and separate from other animals, partly because our animal nature serves as a 
reminder of personal mortality, a highly dissonant cognition (Goldenberg et al., 2001). The second reason is that awareness of animal sentience makes it more difficult to exploit them (Bastian et al., 2012).

\section{References}

Alessandri, J., Darcheville, J.-C., \& Zentall, T. R. (2008). Cognitive dissonance in children: Justification of effort or contrast? Psychonomic Bulletin \& Review, 15, 673-677.

Alessandri, J., Darcheville, J.-C., Delevoye-Turrell, Y., \& Zentall, T. R. (2008). Preference for rewards that follow greater effort and greater delay. Learning \& Behavior, 36, 352-358.

Aronson, E. (1968). Dissonance theory: Progress and problems. In R. P. Abelson, E. Aronson, W. J. McGuire, T. M. Newcomb, M. J. Rosenberg, \& P. H. Tannenbaum (Eds.), Theories of cognitive consistency: A sourcebook (pp. 5-27). Chicago: Rand McNally.

Bastian, B., Loughnan, S., Haslam, N., \& Radke, H. R. (2012). Don't mind meat? The denial of mind to animals used for human consumption. Personality and Social Psychology Bulletin, 38(2), 247-256.

Beauvois, J. L., \& Joule, R. V. (1996). A radical dissonance theory. London: Taylor \& Francis.

Botvinick, M. M., Huffstetler, S., \& McGuire, J. T. (2009). Effort discounting in human nucleus accumbens. Cognitive, Affective, \& Behavioral Neuroscience, 9(1), 16-27.

Chen, M. K., \& Risen, J. L. (2010). How choice affects and reflects preferences: Revisiting the free-choice paradigm. Journal of Personality and Social Psychology, 99(4), 573-594.

Cooper, J., \& Fazio, R. H. (1984). A new look at dissonance theory. Advances in Experimental Social Psychology, 17, 229-266.

Egan, L. C., Bloom, P., \& Santos, L. R. (2010). Choice-induced preferences in the absence of choice: Evidence from a blind two choice paradigm with young children and capuchin monkeys. Journal of Experimental Social Psychology, 46(1), 204-207.

Egan, L. C., Santos, L. R., \& Bloom, P. (2007). The origins of cognitive dissonance evidence from children and monkeys. Psychological Science, 18(11), 978-983.

Forgas, J. P. (1995). Mood and judgment: the affect infusion model (AIM). Psychological Bulletin, 117(1), 39-66.

Gerard, H. B., \& Mathewson, G. C. (1966). The effects of severity of initiation on liking for a group: A replication. Journal of Experimental Social Psychology, 2(3), 278-287.

Goldenberg, J. L., Pyszczynski, T., Greenberg, J., Solomon, S., Kluck, B., \& Cornwell, R. (2001). I am not an animal: Mortality salience, disgust, and the denial of human creatureliness. Journal of Experimental Psychology: General, 130(3), 427-435.

Harmon-Jones, C., Schmeichel, B. J., Inzlicht, M., \& Harmon-Jones, E. (2011). Trait approach motivation relates to dissonance reduction. Social Psychological and Personality Science, 2, 21-28.

Harmon-Jones, E., \& Harmon-Jones, C. (2002). Testing the action-based model of cognitive dissonance: The effect of action orientation on postdecisional attitudes. Personality and Social Psychology Bulletin, 28(6), 711-723.

Harmon-Jones, E., Amodio, D. M., \& Harmon-Jones, C. (2009). Action-based model of dissonance: A review, integration, and expansion of conceptions of cognitive conflict. Advances in Experimental Social Psychology, 41, 119-166. 
Harmon-Jones, E., Harmon-Jones, C., Fearn, M., Sigelman, J. D., \& Johnson, P. (2008). Left frontal cortical activation and spreading of alternatives: Tests of the action-based model of dissonance. Journal of Personality and Social Psychology, 94(1), 1-15.

Harmon-Jones, E., Price, T. F., \& Harmon-Jones, C. (2015). Supine body posture decreases rationalizations: Testing the action-based model of dissonance. Journal of Experimental Social Psychology, 56, 228-234.

Izuma, K., Matsumoto, M., Murayama, K., Samejima, K., Sadato, N., \& Matsumoto, K. (2010). Neural correlates of cognitive dissonance and choice-induced preference change. Proceedings of the National Academy of Sciences, 107(51), 22014-22019.

Steele, C. M. (1988). The psychology of self-affirmation: Sustaining the integrity of the self. Advances in Experimental Social Psychology, 21, 261-302.

Zentall, T. R. (2016). Cognitive dissonance or contrast?. Animal Sentience, 12(1).

Zentall, T. R., \& Singer, R. A. (2007). Within-trial contrast: Pigeons prefer conditioned reinforcers that follow a relatively more rather than less aversive event. Journal of the Experimental Analysis of Behavior, 88, 131-149. 